\title{
Correction to: MicroRNA-351 Promotes the Proliferation and Invasion of Glioma Cells Through Downregulation of NAIF1
}

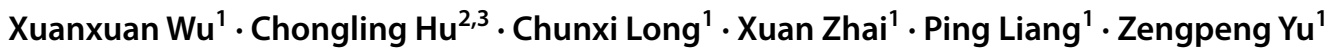

Accepted: 6 September 2021 / Published online: 16 November 2021

๑) Springer Science+Business Media, LLC, part of Springer Nature 2021

Correction to: Journal of Molecular Neuroscience (2020) 70:1493-1499 https://doi.org/10.1007/s12031-020-01582-z

The original version of this article, published on 6 June 2021 , unfortunately contained a mistake. Figure 4 is currently inaccurate. The corrected figure is as follows:

Here, there are three repeats for each sample in each round of our experiments. And three rounds of experiments were performed. There is a tenfold difference between the original measurements and the current measurement due to the oversight on the part of the research team.

Original article has been corrected.

The online version of the original article can be found at https:// doi.org/10.1007/s12031-020-01582-z.

Zengpeng Yu

Zengpeng.Yu85@gmail.com

1 Department of Neurosurgery, Children's Hospital of Chongqing Medical University, Chongqing Key Laboratory of Pediatrics, No. 136 Zhongshan 2nd Road, Chongqing 400014, Yuzhong, China

2 Chongqing Key Laboratory of Translational Research for Cancer Metastasis and Individualized Treatment, Chongqing University Cancer Hospital, No. 181 Hanyu Road, Chongqing 400030, China

3 Department of Neural Tumor, Chongqing Key Laboratory of Translational Research for Cancer Metastasis and Individualized Treatment, Chongqing University Cancer Hospital, No. 181 Hanyu Road, Chongqing 400030, China 

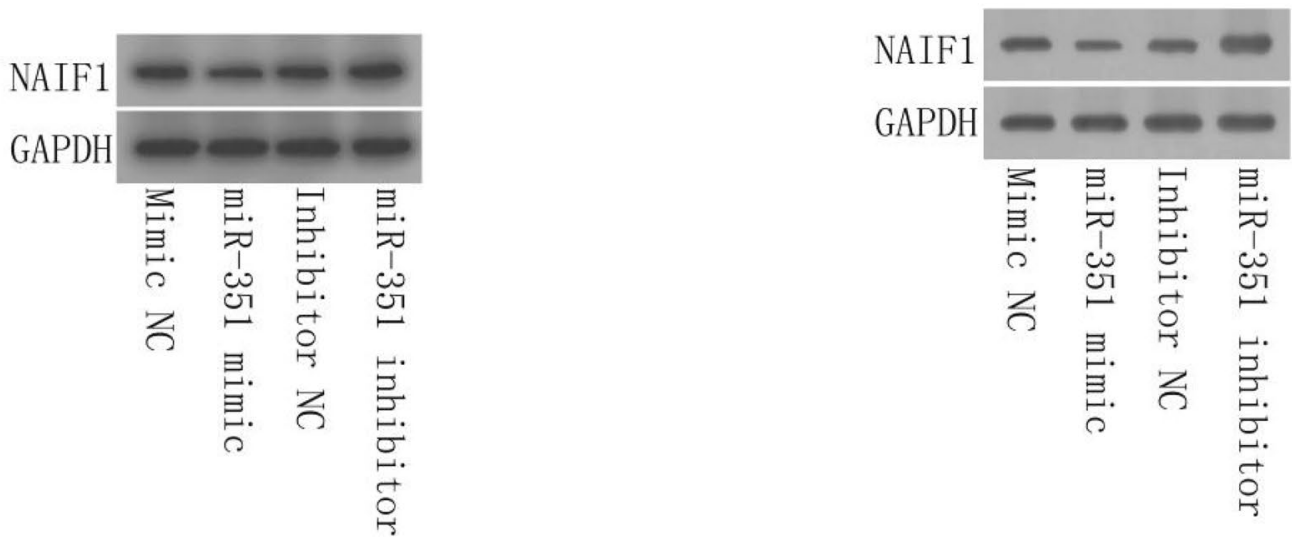

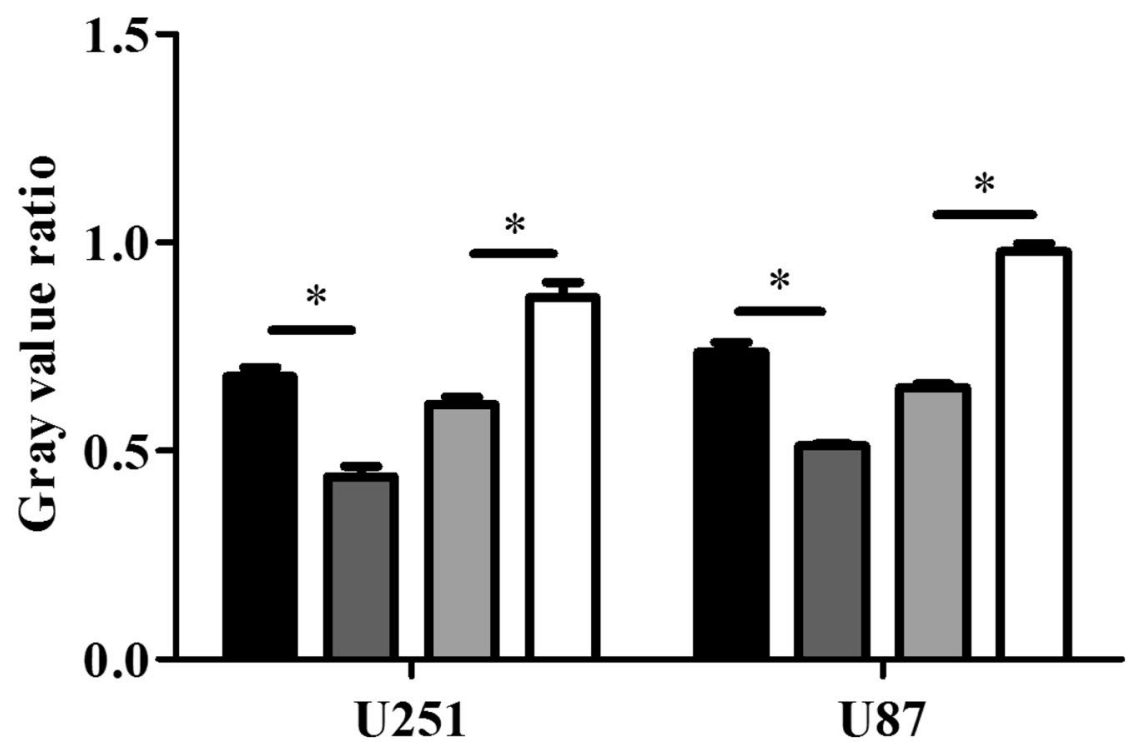

$\square$ Mimic NC

$\square$ miR-351 mimic

$\square$ Inhibitor NC

$\square$ miR-351 inhibitor
Fig. 4 Regulatory effect of miR-351 on the protein level of NAIF1 in glioma cell lines was detected by Western blot. The protein level of NAIF1 was decreased in U251 and U87 cells in the miR-351 mimics group compared with the mimic NC group $(P=0.001$ and $P=0.001$ respectively). Furthermore, the protein level of NAIF1 was increased in U251 and U87 cells in the miR-351 inhibitors group compared with the inhibitor NC group ( $P=0.001$ and $P=0.001$, respectively). Data are represented as mean $\pm \mathrm{SD}$. $* P<0.05$

Publisher's Note Springer Nature remains neutral with regard to jurisdictional claims in published maps and institutional affiliations. 